\title{
Sequence data from isolated lichen-associated melanized fungi enhance delimitation of two new lineages within Chaetothyriomycetidae
}

\author{
Lucia Muggia $^{1}$ - Yu Quan ${ }^{2,3,4}$ • Cécile Gueidan ${ }^{5}$ - Abdullah M. S. Al-Hatmi ${ }^{2,6,7}$ • Martin Grube ${ }^{8}$ - Sybren de Hoog ${ }^{3,7,9,10}$
}

Received: 4 September 2020 / Revised: 26 April 2021 / Accepted: 27 April 2021

(C) The Author(s) 2021

\begin{abstract}
Lichen thalli provide a long-lived and stable habitat for colonization by a wide range of microorganisms. Increased interest in these lichen-associated microbial communities has revealed an impressive diversity of fungi, including several novel lineages which still await formal taxonomic recognition. Among these, members of the Eurotiomycetes and Dothideomycetes usually occur asymptomatically in the lichen thalli, even if they share ancestry with fungi that may be parasitic on their host. Mycelia of the isolates are characterized by melanized cell walls and the fungi display exclusively asexual propagation. Their taxonomic placement requires, therefore, the use of DNA sequence data. Here, we consider recently published sequence data from lichenassociated fungi and characterize and formally describe two new, individually monophyletic lineages at family, genus, and species levels. The Pleostigmataceae fam. nov. and Melanina gen. nov. both comprise rock-inhabiting fungi that associate with epilithic, crust-forming lichens in subalpine habitats. The phylogenetic placement and the monophyly of Pleostigmataceae lack statistical support, but the family was resolved as sister to the order Verrucariales. This family comprises the species Pleostigma alpinum sp. nov., P. frigidum sp. nov., P. jungermannicola, and P. lichenophilum sp. nov. The placement of the genus Melanina is supported as a lineage within the Chaetothyriales. To date, this genus comprises the single species M. gunde-cimermaniae sp. nov. and forms a sister group to a large lineage including Herpotrichiellaceae, Chaetothyriaceae, Cyphellophoraceae, and Trichomeriaceae. The new phylogenetic analysis of the subclass Chaetothyiomycetidae provides new insight into genus and family level delimitation and classification of this ecologically diverse group of fungi.
\end{abstract}

Keywords Black yeast $\cdot$ Fungal lifestyles $\cdot$ Melanina $\cdot$ Ribosomal RNA $\cdot$ nucLSU $\cdot$ Pleostigma

Section Editor: Gerhard Rambold

Lucia Muggia

lmuggia@units.it

1 Department of Life Sciences, University of Trieste, 34127 Trieste, Italy

2 Key Laboratory of Environmental Pollution Monitoring and Disease Control, Ministry of Education of Guizhou \& Guizhou Talent Base for Microbiology and Human Health, School of Basic Medical Sciences, Guizhou Medical University, Guiyang, China

3 Centre of Expertise in Mycology, Radboud University Medical Centre/Canisius Wilhelmina Hospital, Nijmegen, The Netherlands

4 College of Food and Pharmaceutical Engineering, Guizhou Institute of Technology, Guiyang, China
5 Australian National Herbarium, CANBR, National Research Collections Australia, CSIRO, Canberra, Australia

6 Ministry of Health, Directorate General of Health Services, Ibri, Oman

7 Foundation Atlas of Clinical Fungi, Hilversum, The Netherlands

8 Institute of Biology, University of Graz, Graz, Austria

9 Department of Medical Microbiology, People's Hospital of Suzhou National New \& Hi-Tech Industrial Development Zone, Jiangsu, China

10 Postgraduate Program in Microbiology, Parasitology and Pathology, Biological Sciences, Department of Basic Pathology, Federal University of Parana, Curitiba, Brazil 


\section{Introduction}

Lichen symbioses give rise to unique structures. The lichen thallus is that of a shape-determining fungus, the mycobiont, while one or more phototrophic microorganisms, the photobionts (green algae or cyanobacteria), are hosted extracellularly, entangled in a network of fungal hyphae (Hawksworth and Honegger 1994). The lichen thallus is an open, usually long-lived system, which with age provides a habitat for a growing number of additional microorganisms. These comprise other fungi (filamentous and yeast-like), microalgae, and bacteria (Petrini et al. 1990; Hofstetter et al. 2007; Spribille 2018). During the past decade, these complementary microorganisms have become subject of research to understand their role in the lichen symbiosis (e.g., Grube et al. 2009, 2015; Moya et al. 2017; Molins et al. 2018; Muggia and Grube 2018; Spribille 2018).

Lichen-inhabiting fungi have long been recognized in morpho-anatomical analyses (Lawrey and Diederich 2003; Diederich et al. 2018; Muggia and Grube 2018). These lichenicolous fungi cause diagnostic symptoms or formations on their specific lichen hosts, such as recognizable reproductive structures, gall-like hypertrophications, melanized or discolored patches, or senescence of thallus (Lawrey and Diederich 2003). Interactions may occur with diverse degrees of specificity with the photo- or the mycobiont, or with the intercellular matrix of the host (de los Rios et al., 2002). Recently, some of them were included in molecular phylogenetic studies (e.g., Untereiner et al. 2011; Diederich et al. 2013; Suija et al. 2015; Muggia et al. 2015, 2019; Ertz et al. 2016). Various other types of trophic interactions between these lichen-associated fungi and their hosts are noted; however, the role in the symbiosis of these symptomatic commensals is less easy to understand than that of destructive pathogens. Basidiomycetous yeasts have been suggested to act as ubiquitous third symbionts in the upper cortex of lichen thalli (Spribille et al. 2016), although other authors failed to find them in metagenomic surveys (Lendemer et al. 2019; Smith et al. 2020). Microscopy, culture-based experiments, and metabarcoding analyses have emphasized that many other fungi use lichens as a habitat in a hidden life cycle (Petrini et al. 1990; Harutyunyan et al. 2008; U'Ren et al. 2012; Muggia et al. 2016; Gueidan et al. 2019). Fungi with these associations have become known as "endolichenic fungi," as they were isolated from surface-sterilized lichens (Arnold et al. 2009). An unambiguous distinction between endolichenic and lichenicolous lifestyles is difficult since the latter are also known to invade the host thallus. In general, it has become clear that lichens are inhabited by a plethora of other fungi that comprise specific and generalist fractions (Fernandez-Mendoza et al., 2017; Banchi et al. 2018; Muggia and Grube 2018; U'Ren et al. 2019). The lichen mycobiome changes with ecological and growth parameters of the lichen host, but precise interactions have still to be unraveled.

Fluctuations of temperature and humidity are characteristic for sun-exposed rock surfaces. Despite the extreme conditions, these habitats share species-rich lichen communities. The thalli of the epilithic lichens are commonly colonized by filamentous ascomycetes, which are closely related to rockinhabiting or pathogenic black yeasts in the classes Dothideomycetes and Eurotiomycetes (Harutyunyan et al. 2008; Muggia et al. 2016, 2017; Muggia and Grube 2018). Typically, these fungi have dark mycelia due to the accumulation of melanin in the cell walls. The pigmentation confers resistance to high radiation and other abiotic stress conditions, such as desiccation and extreme temperatures (Gostinčar et al. 2012, 2018).

In previous studies, Muggia et al. $(2016,2017)$ provided data on a comprehensive set of strains of culturable fungi isolated from lichens surveyed in an alpine habitat. In addition, an overview was made of their phylogenetic relationships, with special emphasis on members of Dothideomycetes and Eurotiomycetes. Some of the lineages represented earlier described lichenicolous fungi within Chaetothyriomycetidae, specifically in the orders Chaetothyriales and Verrucariales (Muggia et al. 2015, 2019). Others remained unnamed and awaited formal description, anticipating additional knowledge of the extant diversity of these fungi. Relationships within the order Chaetothyriales have been elucidated by Teixeira et al. (2017) and Quan et al. (2020). The enlarged DNA sequence dataset of Chaetothyriomycetidae now available (e.g., Chomnunti et al. 2012; Gueidan et al. 2014; Vasse et al. 2017) facilitates phylogenetic placements of the yet-unnamed lineages of lichen-inhabiting black fungi. This enables fulfilment of a pressing need to establish the nature of yet-unnamed lineages. Here we re-consider these yet-unnamed lineages of lichen-inhabiting black fungi and present a formal description of one new family, one new genus, and four new species. We also reappraise the ancestral lineages within the Chaetothyriales-Verrucariales clade by presenting a phylogenetic analysis for the major orders and families within Chaetothyriomycetidae and discuss on the evolution of their different life styles.

\section{Materials and methods}

\section{Origin of samples: sampling and culture isolation}

The here analyzed lichen-associated fungi were isolated from lichen thalli collected during a survey done as part of a research project carried out between 2012 and 2015 by LM and MG. The lichens were sampled in an Alpine habitat on siliceous-schist and gneissic boulders and cliffs on the Koralpe mountain range in the south-eastern rim of the 
Austrian Alps, between the regions Styria and Carinthia. This mountain region has been characterized for its peculiar flora, as it was not covered by ice during the last ice age (i.e., representing a nunatak; van Husen 1987). Crust-forming lichen thalli were selected (Fig. 1) as reported previously in Fleischhacker et al. (2015) and Muggia et al. (2016, 2017).

The lichen-associated fungi were isolated and cultured following the protocol of Yamamoto et al. (2002) as described in Muggia et al. (2016, 2017). The inocula were placed on six different media in order to promote the growth of different fungi as reported by Muggia et al. (2017). The identity of the isolated fungi was checked by sequencing nuclear and mitochondrial ribosomal RNA gene fragments (Muggia et al. 2016, 2017) and cultures of representative strains were kept alive on agar plates using the same growth medium on which the inoculum was originally isolated successfully. All cultured strains reported in the present study are deposited and are preserved both in a metabolically inactive state and as cryostocks at the University of Graz in the culture collection of the first author (LMCC).

\section{Morphological analyses of cultured strains}

Morphological and anatomical characters of the cultured strains included in the phylogenetic inference and representing the two newly recognized lineages (Melanina gen. nov. and Pleostigmaceae fam. nov., see below) were analyzed using standard microscopic techniques and documented with digital photographs. Analyses and photographs were performed on 10-month-old to 1-year-old subcultures considering the following characters: form of growth (filamentous vs. yeastlike), form and size of hyphal cells, branching of hyphae, development of conidiogenous cells and formation of conidia, melanization. Small fragments of mycelia were removed, and squashed sections were mounted in water and studied by light microscopy. Images were acquired with a ZeissAxioCam MRc5 digital camera fitted to the microscope. Both images of growth habit and hyphae structure were digitally processed using the CombineZM software (www.hadleyweb.pwp. blueyonder.co.uk/). Photos were slightly refined in sharpness and color tone with Adobe Photoshop 7.0, and the figures were prepared with CorelDRAW X4.

\section{Molecular analyses: DNA extraction, amplification, sequencing, and identification}

Sequence data of the studied strains were already available in GenBank as they were published previously by Muggia et al. (2016, 2017). Here, we used the data which were generated for the nucLSU fragment, while additional ITS sequences were recently generated and included in the analyses of Quan et al. (2020). The nucLSU fragment was amplified and sequenced in two parts using primers SR6R (http://www. botany.duke.edu/) and LR5 (upstream), and primers LR3R and LR7 (Vilgalys and Hester 1990) (downstream), as reported by Muggia et al. (2016, 2017). The preparation of the alignment was done in BioEdit (Hall 1999).

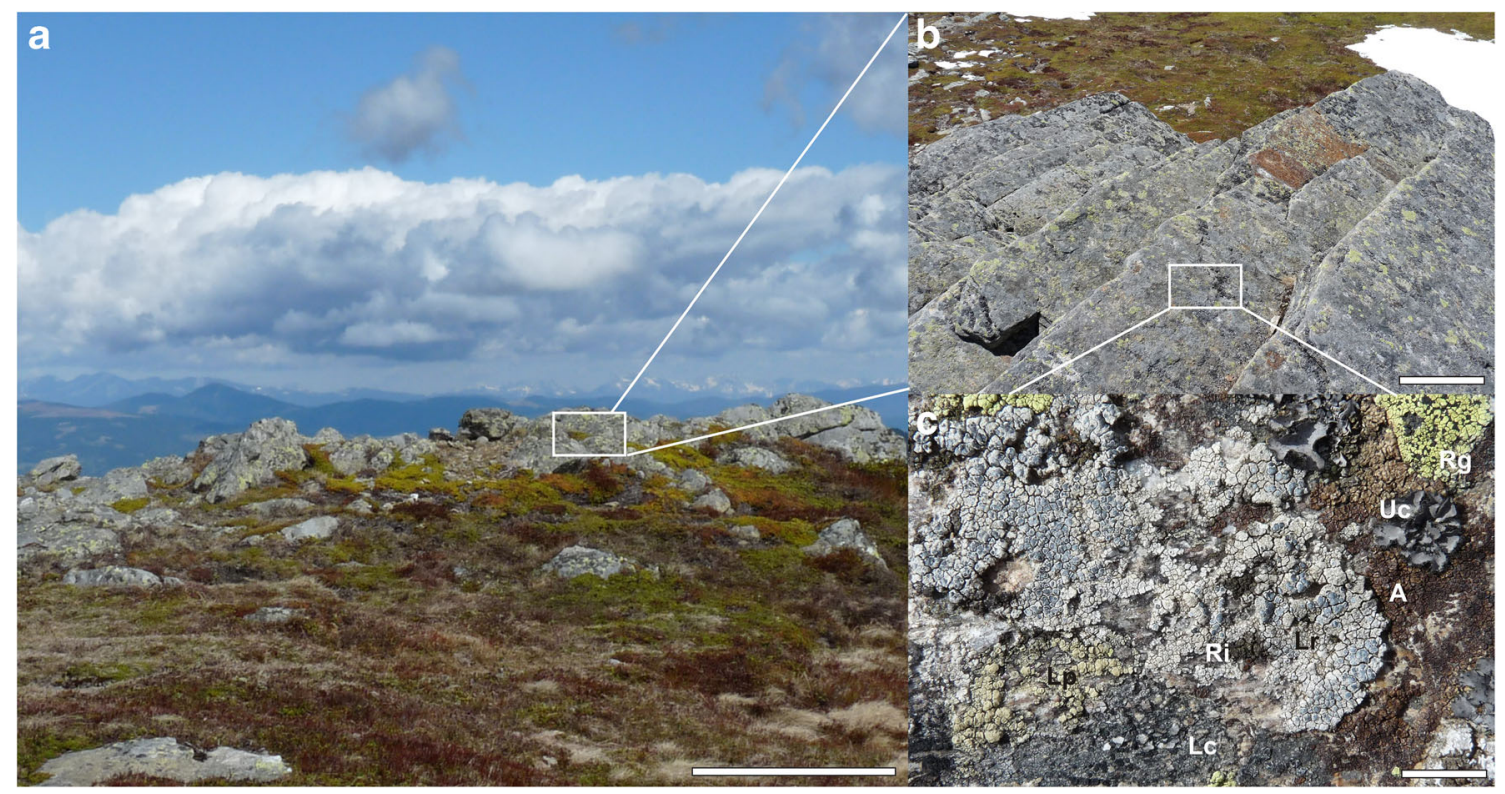

Fig. 1 Ecology of the lichen communities from which the studied chaetothyrialean fungi were isolated. a Overview of the alpine environment with siliceous-schist and gneissic rocks scattered in wide areas of pastures or dwarf shrub formations at $2000 \mathrm{~m}$ a.s.l. b Detailed view of the rock surfaces. c Detailed view of the density of the lichen thalli on rocks; the lichen species are Acarospora sp. (A), Lecidea sp. (Lc), Lecanora polytropa (Lp), Lecanora rupicola (Lr), Rimularia insularis (Ri), Rhizocarpon geographicum (rg), Umbilicaria cylindrica (Uc). Scale bars: a, $2 \mathrm{~m} ; \mathbf{b}, 20 \mathrm{~cm} ; \mathbf{c}, 2 \mathrm{~cm}$ 


\section{Alignment and phylogenetic analyses}

Taxon sampling was that of Muggia et al. $(2016,2017)$ supplemented with relevant sequences available in GenBank. The selection of taxa also considered phylogenetic analyses of Gueidan et al. (2007, 2008, 2011, 2014), Untereiner et al. (2011), Teixeira et al. (2017), Réblová et al. (2017a,b), and Muggia et al. (2015, 2016, 2017, 2019). The present dataset comprises nucLSU sequences belonging to 207 Eurotiomycetes covering the entire class (Table S1), all taxa being represented by a single nucLSU sequence. Of these, 196 taxa are representatives of the subclass Chaetothyriomycetidae, including its four orders: Chaetothyriales (with families Chaetothyriaceae, Cyphellophoraceae, Epibryaceae, Herpotrichiellaceae, Trichomeriaceae, and the "unnamed lineage 3" sensu Gueidan et al. (2014). Phaeomoniellales, Pyrenulales, and Verrucariales (with its sole family Verrucariaceae) and the closely related "unnamed lineage 2" sensu Gueidan et al. (2014). The order Onygenales (Eurotiomycetidae) is represented by four species, and the Sclerococcales by two species (Sclerococcomycetidae; corresponding to the "unnamed lineage 1" sensu Gueidan et al. (2014). The phylogeny was rooted with three taxa belonging to Mycocaliciales (Mycocaliciomycetidae), i.e., Chaenotheca savonica, Sphinctrina turbinata, and Stenocybe pullatula. The selection of the nucLSU locus alone in our phylogenetic analysis is due to the fact that sequence data for the nucSSU and $\mathrm{mtSSU}$ loci are missing for the majority of the compared taxa. However, the identity of cultured fungal strains was originally studied also using partial sequences of the nuclear large and nuclear small ribosomal subunits and the mitochondrial small ribosomal subunit (Muggia et al. 2016, 2017).

Introns and ambiguously aligned regions were removed from the alignment. The nucLSU dataset was analyzed with a maximum likelihood (ML) (Mason-Gamer and Kellogg 1996; Reeb et al. 2004) and a Bayesian approach. The final sequence alignment used for the analyses is available as supplementary material. The ML analysis was performed using the program RAxML v8.2 (Stamatakis 2014) applying the GTRGAMMA model and running 1000 bootstrap replicates. The Bayesian analysis was run with the program MrBayes v3.2.5 (Ronquist et al. 2011). Two runs of four simultaneous Markov chains were run for 2,000,000 generations, and trees were sampled every 100th generation. MCMC-heated chain was set with a "temperature" value of 0.15 . The distribution of log-likelihood scores was examined using the program Tracer v1.5 (Rambaut and Drummond 2009) to determine that stationary phase for each search was reached and chains had achieved convergence. The first $25 \%$ of the sampled topologies were discarded as part of a burn-in procedure, while the remaining trees were used for calculating the posterior probabilities in the majority rule consensus tree. The convergence of the chains was also confirmed by the convergent diagnostic of the potential scale reduction factor (PSRF), which approached 1 (Ronquist et al. 2011). The phylogenetic trees were visualized in TreeView v1.6.6 (Page 1996).

\section{Results}

\section{Phylogeny}

ML and Bayesian analyses were found to be topologically concordant with each other (Fig. 2) and with previously and presently published phylogenetic inferences of Eurotiomycetes based on nucLSU and further combined nuclear and mitochondrial loci (Gueidan et al. 2008, 2011, 2014; Teixeira et al. 2017; Muggia et al. 2015, 2016, 2017, 2019; Quan et al. 2020). All major orders in Chaetothyriomycetidae and all families in Chaetothyriales are fully resolved as monophyletic and highly supported (95-100\% bootstrap value, PP $>95 \%$ ). The order Verrucariales is here only represented by the family Verrucariaceae. This family includes lichenized taxa and a small lineage represented by endolichenic fungi, recently reported by Muggia et al. (2019). The latter group likely represents lichenicolous fungal species of the genus Muellerella.

The majority of sequences belonging to the endolichenic fungi are resolved into two main lineages, here named Pleostigmaceae fam. nov. and Melanina gen. nov., while the five remaining sequences are placed in the Cladophialophora clade within Herpotrichiellaceae (A1033, A1044, A1069, A1102 and A1123), one in Epibryaceae (A515), and one in Pyrenulales (A1133). The two new lineages of Pleostigmaceae and Melanina correspond to those highlighted in Gueidan et al. (2014) and Réblová et al. (2017a, b) under the names "unnamed lineage 2" and "unnamed lineage 3," and in Muggia et al. (2016, 2017) under the names "clade IV" and "clade V," "clade VI," and "clade VII", respectively. This correspondence is here evident by the fact that the three sequences of Chaetothyriales TRN242, Chaetothyriales A14, and Pleostigma jungermannicola M174 - representing the original "unnamed lineage 2" sensu Gueidan et al. (2014) - cluster with the strains recognized as "clade IV" and "clade V" sensu Muggia et al. (2016, 2017), i.e., the new family Pleostigmataceae. Similarly, sequences of the two rock-inhabiting fungi TRN508 and TRN210 - originally recognized as "unnamed lineage 3" sensu Gueidan et al. (2014) - cluster with the strains of "clade VI" and "clade VII" sensu Muggia et al. (2016, 2017), i.e., the new genus Melanina.

The new family Pleostigmaceae is not statistically supported but is placed sister to the Verrucariales, and both are sister to the Chaetothyriales, although none of these relationships is supported (Fig. 2). Members of the Pleostigmataceae are morphologically highly similar, but sequence diversity allows 


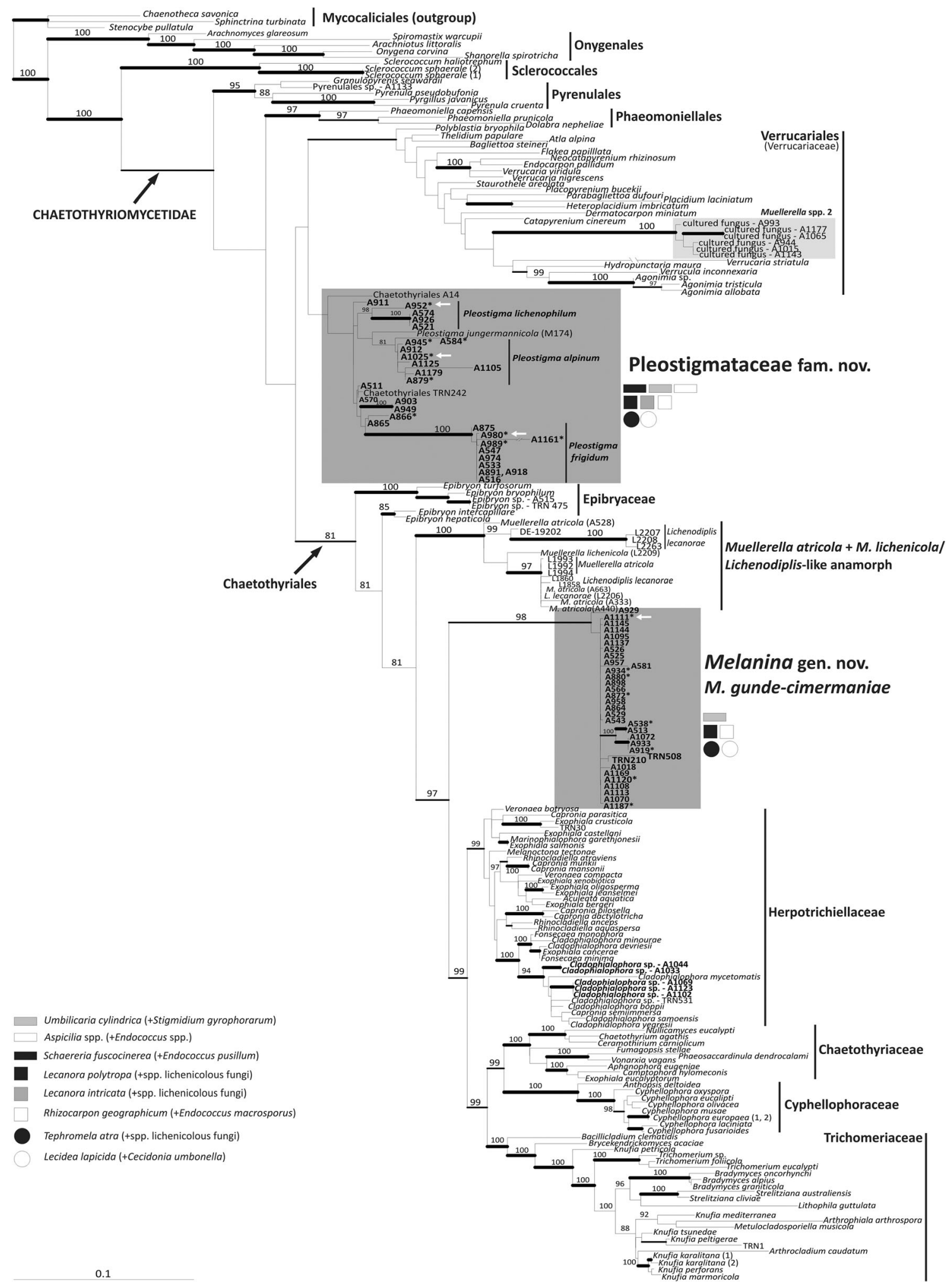

Fig. 2 Maximum likelihood phylogenetic analysis based on the nucLSU sequences of Eurotiomycetes. The ML and Bayesian topology were identical. The newly identified lineages of Pleostigmataceae and Melanina are highlighted and strain numbers are reported in bold. The type strains are indicated by a white arrow. Asterisks mark the samples in

the photo tables (Figs. 4, 5, and 6). Posterior probability (PP) values $>80$ are reported above branches, while ML bootstrap supports are indicated by the thickness of the branches: the thickest, fully supported 96-100\%; middle thick, well-supported 70-95\%; no thickness, poorly supported lower than $70 \%$. The scale bar is proportional to the substitution rate 
recognizing three highly supported (PP $>98 \%$; bootstrap values $>80$ ) sub-clades, which are here described as new species. The three new species Pleostigma alpinum, $P$. frigidum, and $P$. lichenophilum are well-supported either by ML or Bayesian analyses, or both. In addition, six strains of endolichenic fungi and the sample Chaetothyriales TRN242 are basal to $P$. frigida but do not form a separate monophyletic clade. This placement still prevents either their inclusion in the $P$. frigida clade, or to recognized them as a separate taxonomic unit. The sequence of Pleostigma jungermannicola M174 is basal to Pleostigma alpinum, albeit unsupported. The sample Chaetothyriales A14 is an individual branch at the base of the whole Pleostigmataceae lineage. The entire Pleostigmataceae lineage is unsupported, and this might impair its reliable phylogenetic placement inferred here.

The order Chaetothyriales includes (i) the family Epibryaceae, which is paraphyletic and basal to the order, splitting into two highly supported lineages; (ii) the monophyletic clade of the ascus-forming species Muellerella atricola + M. lichenicola and their asexual form Lichenodiplis (as recognized in Muggia et al. 2015, 2019); (iii) the new monophyletic lineage Melanina gen. nov. represented by strains which are genetically almost identical and are described as the new species M. gunde-cimermaniae; and (iv) the remaining families Chaetothyriaceae, Cyphellophoraceae, Herpotrichiellaceae, and Trichomeriaceae.

\section{Morphology}

The new lineages Pleostigmataceae and Melanina share similar morphological traits (Figs. 3, 4, 5, and 6), although they are clearly not closely related phylogenetically. Strains of both lineages are characterized by dense, melanized, mainly filamentous mycelia, which grow in a compact form on agar media (Figs. 3a-f; $4 \mathrm{a}-\mathrm{o}, \mathrm{r}-\mathrm{u}, \mathrm{z} ; 5 \mathrm{a}-\mathrm{k}, \mathrm{n}-\mathrm{s}$; and 6a-g, k, 1). In some cases, the mycelia grow in a yeast-like form, producing a rather gelatinous mass from which filamentous hyphae extend (Figs. 4n and 6c, g, 1). Peripheral hyphae and hyphal tips, being the younger parts of the mycelium, are not homogeneously melanized, sometimes almost hyaline (Figs. 3c, $\mathrm{d}, \mathrm{f} ; 4 \mathrm{q}, \mathrm{w}-\mathrm{y} ; 51, \mathrm{~m}$; and $6 \mathrm{o}, \mathrm{q}, \mathrm{r}$ ) conferring a paler tone to the surface of the mycelium. Intense melanization is invariably observed in the hyphae of the central, older parts of the colonies (e.g., Fig. 5e, g-k, n-s). In Pleostigmaceae, hyphal cells are rather elongated with a rectangular shape, but usually assume a spherical form, in correspondence with the branching (Figs. 4b, f, g, k, m and 5e, g, h, k, n-p, s). These spherical cells either subtend multiple branches or they divide in a meristematic fashion at the site where each cell generates a ramification (Fig. 4b, f, g, k, m). In Melanina, hyphae are composed of smaller cells, usually spherical and generated by lateral and apical cell divisions (Fig. 6h, i, m-v) and clumps of conidia have been observed (Fig. 5h, j).
Detailed descriptions of morphological traits of each new lineage are reported below in the "Taxonomy" section.

\section{Taxonomy}

Pleostigmataceae Grube, Muggia, de Hoog, fam. nov.MycoBank: MB838771 (Figs. 3, 4, and 5)

Etymology. The family is named after the genus Pleostigma, which is here identified to belong to Chaetothyriomycetidae.

Type genus: Pleostigma Kirschst.-MycoBank MB4236 (Figs. 3, 4, and 5)

Diagnosis: melanized filamentous fungi, endolichenic and bryophilous, mycelium dark gray to black, hyphae septate, hyaline to heavily melanized, toruloid, yeast-like growth observed in cultured mycelium

Incertae sedis family, phylogenetically close to the orders Verrucariales and Chaetothyriales, Ascomycota, containing the genus Pleostigma. Comprising bryosymbiotic, rockinhabiting and endolichenic melanized fungi; for the latter group, the sexual morph is unknown.

Pleostigma Kirschst.-Annals Mycol. 37(1/2): 91 (1939)—MycoBank: MB4236

Pleostigma alpinum Grube, Muggia, de Hoog, sp. nov.MycoBank: MB838768 (Fig. 3)

Etymology: The species name refers to the Alpine sampling location.

Holotype: GZU A1025 (LMCC0348), cultured strain, preserved in a metabolically inactive state (20 November 2013, date at which it was first identified from culture isolates, isolated from the thallus of Rhizocaron geographicum (GZU A666), Austria, Styria, Central Alps, Steirisches Randgebirge, Koralpe, Ochsenofen, ca. 14 km W above Schwanberg, in the vicinity of the summit, on big boulders NW $46^{\circ} 46^{\prime} 29^{\prime \prime} \mathrm{N} / 15^{\circ} 00^{\prime} 52^{\prime \prime} \mathrm{E}$, ca. $1760 \mathrm{~m}$, on siliceous rocks, 18.VII.2012, L. Muggia \& A. Fleischhacker.

Isotype: GZU A1105.

Diagnosis: Endolichenic (i.e., cryptically present in lichen thalli), asexual fungus, for which the sexual morph is unknown. Axenically cultured colonies, likely derived from asexual spores or hyphal fragments entrapped in the thalline matrix of the lichen hosts, grow in vitro rather slowly; mycelium dark gray to black. Filamentous hyphae at the surface and at the margins of the colony usually hyaline or slightly melanized (Fig. 6c-f); yeast-like growth in the central internal part of the colony; cell walls slightly verrucose. Hyphae septate, hyaline to heavily melanized, toruloid, 3-5 $\mu \mathrm{m}$ thick: hyphal cells rather elongate in a rectangular shape, usually spherical in correspondence of the branching. Spherical cells 7-10 $\mu \mathrm{m}$ wide, at branching either subtending multiple branches or dividing in a meristematic fashion and each cell 
Fig. 3 Morphological characters of Pleostigma alpinum. a, c Strain A1025 (type). b, d Strain A879. e Strain A584. f Strain A945. a, b Colony appearance on solid malt yeast medium after one year of growth. c-f Less melanized hyphae on the upper/tip hyphae of the mycelium. Scale bars: $\mathbf{a}-\mathbf{c} 2$ $\mathrm{mm}$; d, f $0.5 \mathrm{~mm}$; e $0.4 \mathrm{~mm}$
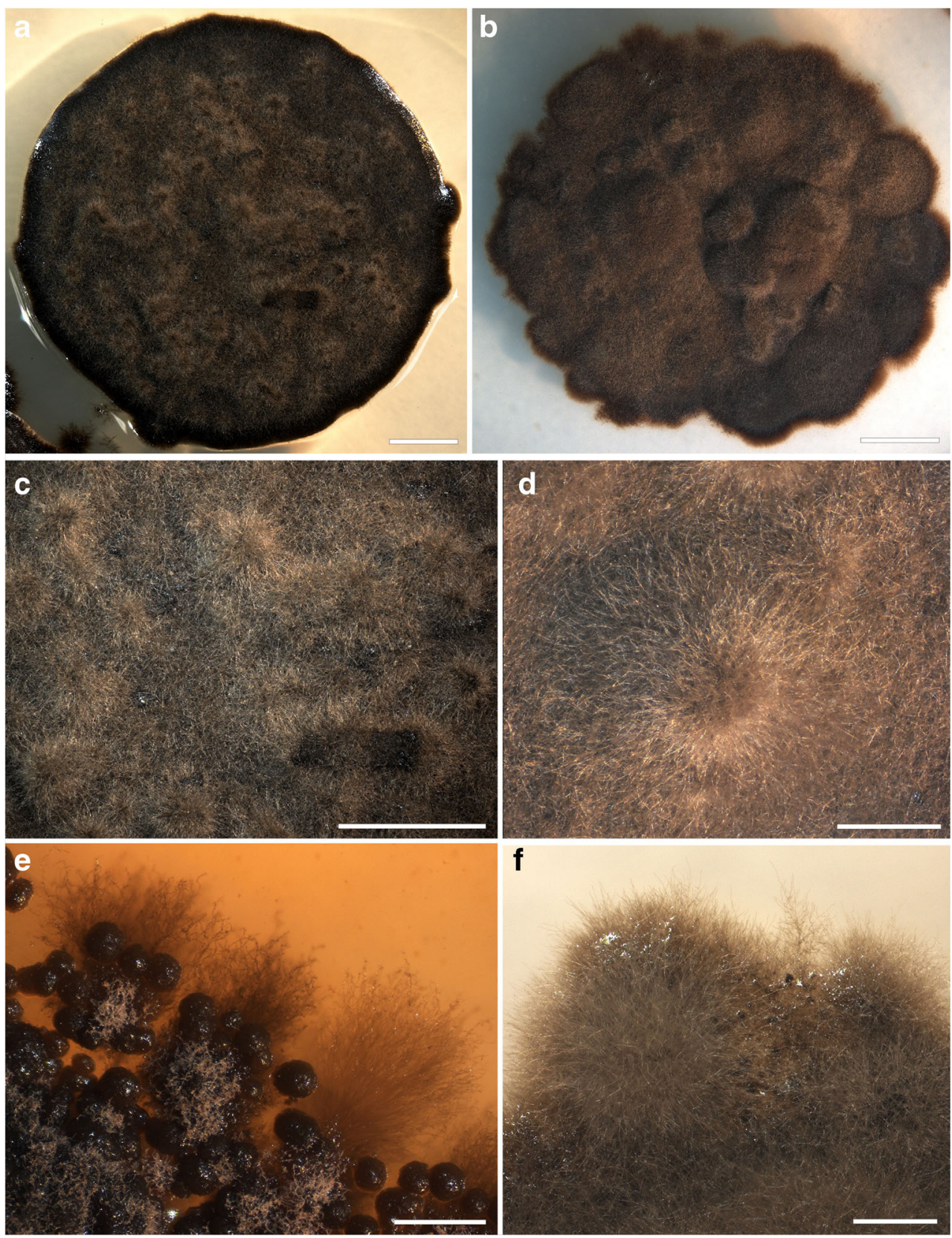

generating a new ramification. $P$. alpinum differs from the type species $P$. jungermannicola by the lack of ascomata and its endolichenic life style. No morphological traits can be compared in cultured strains, as $P$. jungermannicola has never been isolated in culture.

Distribution: Boreal, thus far isolated form alpine lichens, growing on siliceous-schist rocks at about $2000 \mathrm{~m}$ a.s.l. and rock from Mediterranean habitats and bryophytes. Isolated from the following lichen species: Aspicilia caesiocinerea; A. simoensis; Aspicilia sp.; Lecanora intricata; L. polytropa; Lecidea lapicida; Lecidea sp.; Rhizocarpon geographicum; Schaereria fuscocinerea; Tephromela atra; and Umbilicaria cylindrica.
Material examined: EUROPE, Austria, Koralpe mountain range, on siliceous-schist and gneissic rocks, alt. 1800-2100 $\mathrm{m}$ a.s.l., endolichenic fungi isolated from lichen thalli, MayJuly 2012, L. Muggia and A. Fleischhacker, strain numbers A584, A879, A912, A945, A1105, A1125, and A1179.

Notes: Axenically isolated strains are reported in Table S1 and in Muggia et al. (2016, 2017).

Pleostigma frigidum Grube, Muggia, de Hoog, sp. nov.MycoBank: MB838769 (Figs. 4, 5)

Etymology: The species name refers to the ecology, i.e., cold and Alpine, characteristic of the environment from which the strains were isolated. 

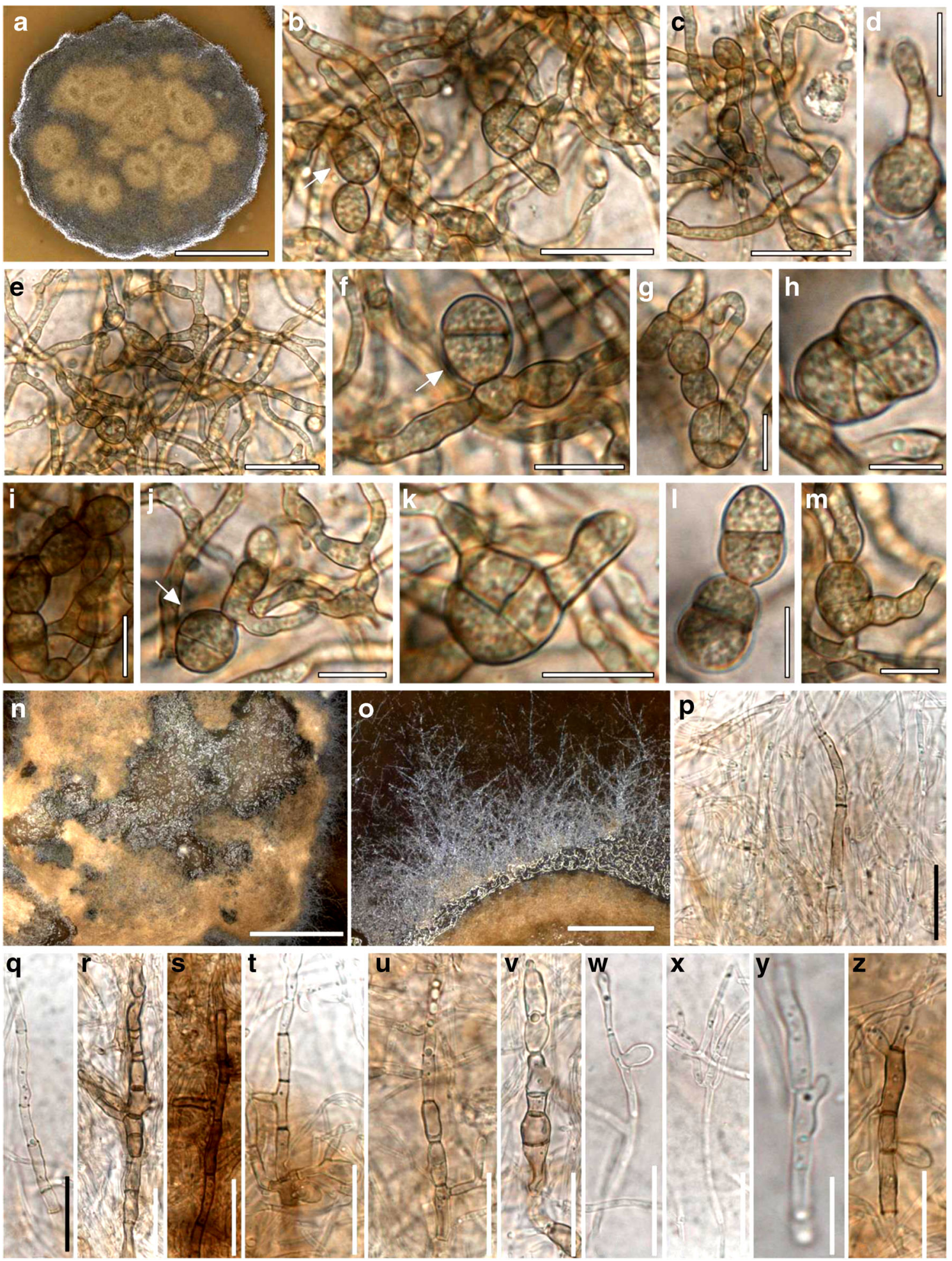

Fig. 4 Morphological characters of Pleostigma frigidum and P. lichenophilum. a-m Strain A952 (type), Pleostigma lichenophilum. n-z Strain A866, Pleostigma frigidum. a, n, o Colony appearance on solid malt yeast medium after 1 year of growth: superficial and marginal filamentous hyphae (a, o) and yeast-like growth in the central internal part (n). b-m Melanized, toruloid hyphae with the formation of

septate $(\mathbf{b}, \mathbf{f}, \mathbf{j}, \mathbf{I})$ or muriform conidiogenous cells $(\mathbf{g}, \mathbf{h}, \mathbf{k}, \mathbf{m})$ often bearing germinating hyphae $(\mathbf{d}, \mathbf{g}, \mathbf{k}, \mathbf{m})$. $\mathbf{q}-\mathbf{z}$ Filamentous, septate hyphae with diverse degree of melanization (subhyaline to pale brown) and branching. Scale bars: a, n 5 mm; $\mathbf{o} 1 \mathrm{~mm} ; \mathbf{b}, \mathbf{c}, \mathbf{e}, \mathbf{p}-\mathbf{z} 20$ цm; d, f-m 10 цm 

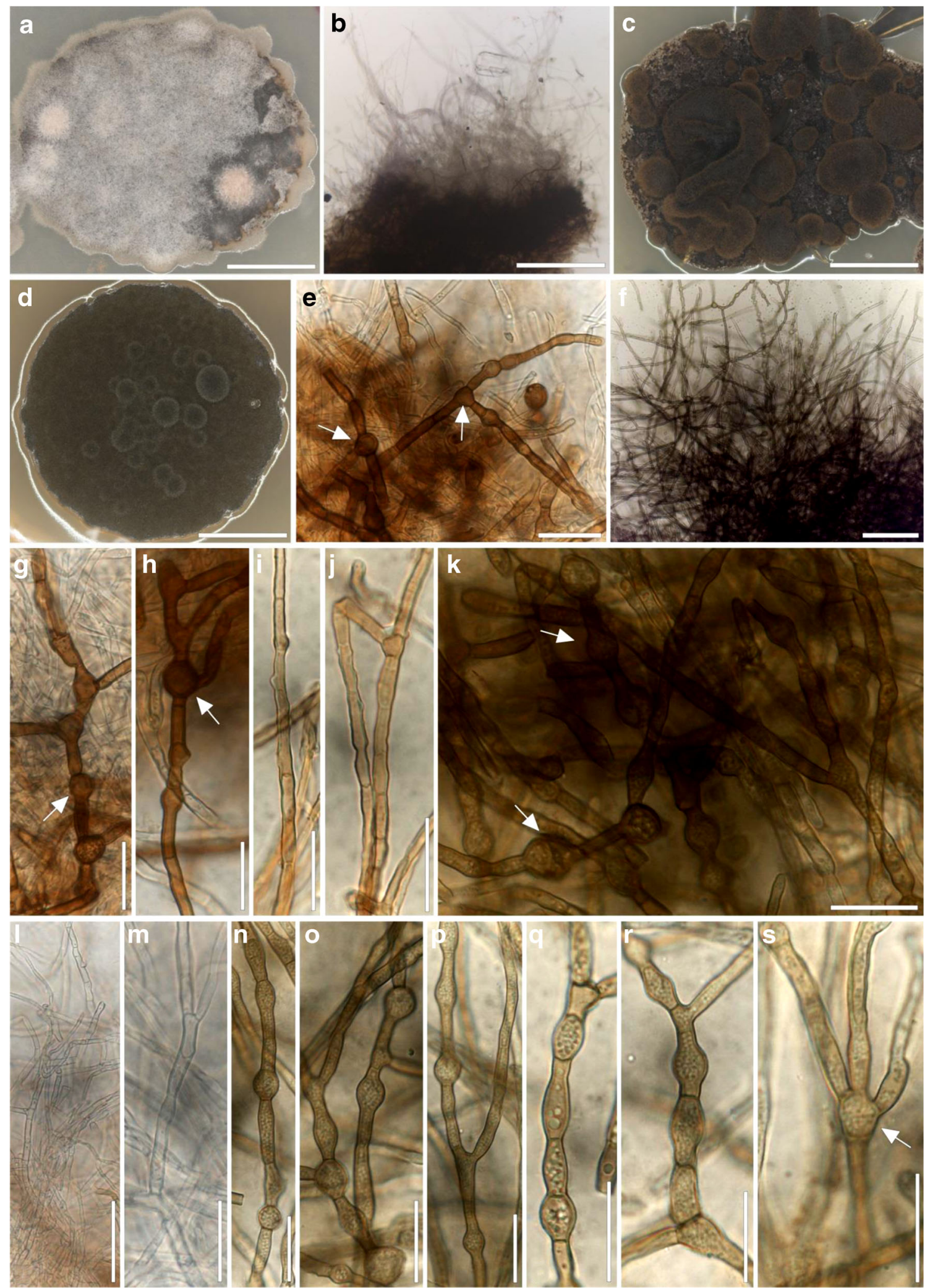

Fig. 5 Morphological characters of Pleostigma frigidum. a, b, e, $, \mathbf{g}, \mathbf{h}, \mathbf{l}, \mathbf{m}$ Strain A1161. c, i, j Strain A989. d, f, k, n-s Strain A980 (type). a-d Colony appearance on solid malt yeast medium after one year of growth. e-s Hyphae morphology: brown, septate, toruloid hyphae, with

accentuate spherical cell at the branching or interposed along the hyphae length. Scale bars: a, c, d 5 mm; b $0.2 \mathrm{~mm}$; f 100 цm; e, g-s 20 цm 

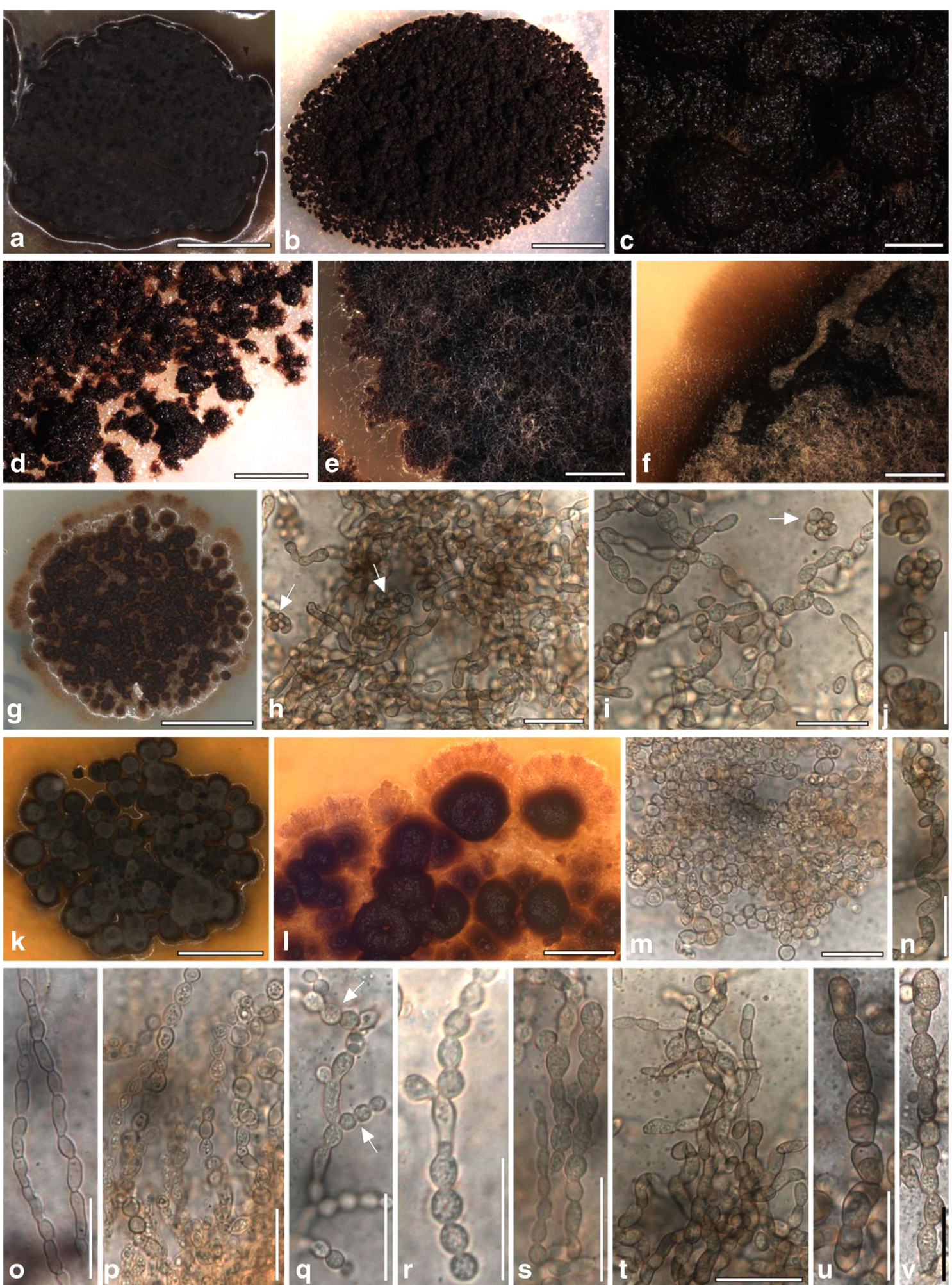

Fig. 6 Morphological characters of Melanina gunde-cimermaniae. Strains a, o A934; b, d A872; c A538; e A880; f A919; g-j, n, t A1163; k, q-s A1111 (type); l, m, p A1187; and u, v, A1120. a-g, k, l Colony appearance on solid malt yeast medium after 1 year of growth. $\mathbf{h}-$ $\mathbf{j}, \mathbf{m}-\mathbf{s}$ Toruloid hyphal organization and filaments of conidia, likely

resulting from a blastic-percurrent ontogeny. $\mathbf{h}-\mathbf{j}, \mathbf{q}$ Clumps of conidia (arrows in H, I, Q). t- $-\mathbf{v}$ Chain of conidia likely resulting from an arthric ontogeny. Scale bars: a, k $5 \mathrm{~mm}$; b $4 \mathrm{~mm}$; c $0.4 \mathrm{~mm}$; d, e, $11 \mathrm{~mm}$; f 0.5 $\mathrm{mm} ; \mathbf{m}-\mathbf{v} 20$ цm 
Holotype: GZU-A980 (LMCC0317), cultured strain, preserved in a metabolically inactive state (20 November 2013, date at which they were first identified from culture isolates). isolated from the thallus of Tephromela atra (A675, GZU 000329462, Austria, Styria, Central Alps, Steirisches Randgebirge, Koralpe, Ochsenofen, ca. 14 km W above Schwanberg, in the vicinity of the summit, on big boulders $\mathrm{NW} 46^{\circ} 46^{\prime} 29^{\prime \prime} \mathrm{N} / 15^{\circ} 00^{\prime} 52^{\prime \prime} \mathrm{E}$, ca. $1760 \mathrm{~m}$, on siliceous rocks, 18.VII.2012, L. Muggia \& A. Fleischhacker.

Isotype: GZU-A989.

Diagnosis: Endolichenic (i.e., cryptically present in lichen thalli), asexual fungus, for which the sexual morph is unknown. Axenically cultured colonies, likely derived from asexual spores or hyphal fragments entrapped in the thalline matrix of the lichen hosts, grow in vitro rather slowly; mycelium dark gray to black. Filamentous hyphae at the surface and at the margins of the colony usually hyaline or slightly melanized; yeast-like growth in the central internal part of the colony; cell walls slightly verrucose. Hyphae septate, hyaline to heavily melanized, toruloid, 3-5 $\mu \mathrm{m}$ thick (Figs. 4q-z and $5 \mathrm{~g}-\mathrm{j}, 1-\mathrm{s}$ ); hyphal cells rather elongate in a rectangular shape, usually spherical in correspondence of the branching. Spherical cells 7-10 $\mu \mathrm{m}$ wide, at branching either subtending multiple branches or dividing in a muriform fashion and each cell generating a new ramification (Fig. $4 \mathrm{~m}$ ). P. frigidum differs from the type species $P$. jungermannicola by the lack of ascomata and its endolichenic life style. No morphological traits can be compared in cultured strains as $P$. jungermannicola has never been isolated in culture.

Distribution: Thus far isolated from lichens and bryophytes. Lichens were growing on siliceous-schist rocks at about $2000 \mathrm{~m}$ a.s.1. in the Alpine area and on rock in Mediterranean habitats. Isolated from the following lichen species: Aspicilia caesiocinerea; A. simoensis; Aspicilia sp.; Lecanora intricata; L. polytropa; Lecidea lapicida; Lecidea sp.; Rhizocarpon geographicum; Schaereria fuscocinerea; Tephromela atra; and Umbilicaria cylindrica.

Material examined: EUROPE, Austria, Koralpe mountain range, on siliceous-schist and gneissic rocks, alt. 1800-2100 $\mathrm{m}$ a.s.1., endolichenic fungi isolated from lichen thalli, MayJuly 2012, L. Muggia and A. Fleischhacker, strain numbers A516, A533, A547, A875, A891, A918, A974, A980, A989, and A1161.

Notes: Axenically isolated strains are reported in Table S1 and in Muggia et al. (2016, 2017).

Pleostigma jungermannicola (C. Massal.) Kirschst. Annals Mycol. 37: 91 (1939)—MycoBank: MB268477

Pleostigma lichenophilum Grube, Muggia, de Hoog, sp. nov.-MycoBank: MB838770 (Fig. 4)

Etymology: The species name refers to the endolichenic lifestyle of the fungus.
Holotype: GZU-A952 (LMCC0289), cultured strain, preserved in a metabolically inactive state (20 November 2013, date at which they were first identified in culture isolation). Isolated from the thallus of Tephromela atra (A675, GZU 000329462, Austria, Styria, Central Alps, Steirisches Randgebirge, Koralpe, Loskogel S der Weinebene, im

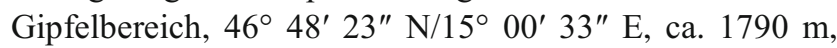
15.V.2012, L. Muggia \&, leg. A. Fleischhacker.

Isotype: GZU-A926 (LMCC0304).

Diagnosis: Endolichenic (i.e., cryptically present in lichen thalli), asexual fungus, for which the sexual morph is unknown. Axenically cultured colonies, likely derived from asexual spores or hyphal fragments entrapped in the thalline matrix of the lichen hosts, grow in vitro rather slowly; mycelium dark gray to black. Filamentous hyphae at the surface and at the margins of the colony usually hyaline or slightly melanized; yeast-like growth in the central internal part of the colony; cell walls slightly verrucose. Hyphae septate, hyaline to heavily melanized, toruloid, 3-5 $\mu \mathrm{m}$ thick: hyphal cells rather elongate in a rectangular shape, usually spherical in correspondence of the branching. Spherical cells 7-10 $\mu \mathrm{m}$ wide, at branching either subtending multiple branches or dividing in a muriform fashion and each cell generating a new ramification (Fig. $5 \mathrm{~g}, \mathrm{k}, \mathrm{m}$ ). P. lichenophilum differs from the type species $P$. jungermannicola for the lack of ascomata and its endolichenic life style. No morphological traits can be compared in cultured strains as $P$. jungermannicola has never been isolated in culture.

Distribution: Boreal, thus far isolated form alpine lichens growing on siliceous-schist rocks at about $2000 \mathrm{~m}$ a.s.1. and rock from Mediterranean habitats, and bryophytes. Isolated from the following lichen species: Aspicilia caesiocinerea; A. simoensis; Aspicilia sp.; Lecanora intricata; L. polytropa; Lecidea lapicida; Lecidea sp.; Rhizocarpon geographicum; Schaereria fuscocinerea; Tephromela atra; and Umbilicaria cylindrica.

Material examined: EUROPE, Austria, Koralpe mountain range, on siliceous-schist and gneissic rocks, alt. 1800-2100 $\mathrm{m}$ a.s.l., endolichenic fungi isolated from lichen thalli, MayJuly 2012, Lucia Muggia and Antonia Fleischhacker, strain numbers A521, A574, A926, and A952.

Notes: Axenically isolated strains as reported in Table S1 and in Muggia et al. $(2016,2017)$.

Melanina Grube, Muggia, de Hoog, gen. nov.MycoBank: MB838740 (Fig. 6)

Etymology: The genus name refers to the melanized mycelium, and therefore its inclusion in the group of "melanized, black fungi."

Type species: Melanina gunde-cimermaniae Grube, Muggia, de Hoog-MycoBank: MB838767 (Fig. 6)

Monotypic genus in the order Chaetothyriales, Ascomycota. Endolichenic fungi, for which the sexual morph 
is unknown. Colonies growing rather slowly in vitro, dark gray to black. Hyphae toruloid, hyaline to heavily melanized. Superficial hyaline hyphae rare; yeast-like growth in the central internal part of the colony, cell walls slightly verrucose. Conidia pale pigmented, organized in chains, likely resulting from a blastic-percurrent or arthric ontogeny.

Melanina gunde-cimermaniae Grube, Muggia, de Hoog, sp. nov.-MycoBank: MB 838767 (Fig. 6)

Etymology. The species is named in honor of the Slovenian mycologist and microbiologist Nina Gunde-Cimerman, who has contributed significantly to the knowledge of stress tolerance of black yeasts.

Holotype: GZU-A1111 (LMCC0452), cultured strain, preserved in a metabolically inactive state $(20$ November 2013 , date at which they were first identified from culture isolates). Isolated from the thallus of Rhizocarpon geographicum (GZU A697), Austria, Styria, Central Alps, Steirisches Randgebirge, Koralpe, Ochsenofen, ca. $14 \mathrm{~km} \mathrm{~W}$ above Schwanberg, in the vicinity of the summit, on big boulders NW, $46^{\circ} 46^{\prime} 30^{\prime \prime} \mathrm{N} / 15^{\circ}$ $00^{\prime} 50^{\prime \prime}$ E, 18.VII.2012, L. Muggia and A. Fleischhacker.

Isotype: GZU-A1120.

Diagnosis: Endolichenic (cryptically present in lichen thalli), asexual fungi. Colonies growing extremely slowly in vitro (reaching $1.5 \mathrm{~cm}$ in a year), dark gray to black. Hyphae toruloid, composed of almost isodiametric cells, 4-5 $\mu \mathrm{m}$ wide, hyaline to heavily melanized. Superficial, hyaline hyphae rare; yeast-like growth present in the central internal part of the colony, with slightly verrucose cell walls. Conidia pale pigmented, 3-4 $\mu \mathrm{m}$ wide organized in chains, likely resulting from a blastic-percurrent or arthric ontogeny.

Distribution: Isolated form alpine lichens growing on siliceous-schist rocks scattered in wide, alpine areas of pastures or dwarf shrub formations, between $1800 \mathrm{~m}$ and $2100 \mathrm{~m}$ a.s.l., and from calcareous rocks in dry Mediterranean habitat (Spain). Isolated from the following lichen species: Lecanora polytropa; Lecidea lapicida; Lecidea sp.; Rhizocarpon geographicum; Tephromela atra; and Umbilicaria cylindrica.

Material examined EUROPE, Austria, Koralpe mountain range, on siliceous-schist and gneissic rocks, alt. 1800-2100 m a.s.l., endolichenic fungi isolated from lichen thalli, May-July 2012, Lucia Muggia and Antonia Fleischhacker, strain numbers A513, A525, A526, A529, A538, A543, A566, A581, A864, A872, A880, A898, A919, A933, A929, A934, A957, A958, A1018, A1070, A1072, A1095, A1108, A1111, A1113, A1120, A1137, A1144, A1145, A1169, and A1187.

Notes: Axenically isolated strains are reported in Table S1 and in Muggia et al. $(2016,2017)$.

\section{Discussion}

Large sequencing efforts conducted during the past decade have progressively contributed in clarifying and reconsidering evolutionary relationships of fungi in the class Eurotiomycetes. Particularly, study of the diverse evolutionary lineages emerging from less frequently explored ecological niches has led to the discovery of numerous novel taxa and to better understanding of their various lifestyles (Stenroos et al. 2010; Chen et al. 2015; Teixeira et al. 2017). Black fungi that grow asymptomatically inside lichen thalli (Harutyunyan et al. 2008; Muggia et al. 2016, 2017; Muggia and Grube 2018), in a similar way as endophytes do (Arnold et al. 2009; U'Ren et al. 2010, 2012, 2019), are also known as endolichenic fungi and form a polyphyletic group in this remarkably ecologically variable class. These fungi have been found to be ancestral to the chaetothyrialean "sooty molds" (colonizers of inert surfaces) and, at larger phylogenetic distance, to opportunists on mammal hosts (Quan et al. 2020).

Because the description of new taxa in this fungal group requires comprehensive sampling, morphological characterization in vitro, and sequencing efforts for inferring their phylogenetic positions, only very few species have been formally described yet. Quan et al. (2020) provided an extensive phylogenetic overview of Chaetothyriales (based on nucLSU and ITS loci), and corroborated the phylogenetic placement of two lineages of black fungi isolated from lichens by Muggia et al. $(2016,2017)$, and of some bryosymbiotic and rock-inhabiting taxa (Stenroos et al. 2010; Gueidan et al. 2014). Both lineages are now represented by multiple strains isolated from different lichen thalli and are here formally introduced as the new family Pleostigmataceae, close to the order Verrucariales, and the new genus Melanina in Chaetothyriales.

Our phylogenetic inference, although based on the single nucLSU locus, is topologically in agreement with previous results based on multiple markers (Gueidan et al. 2014; Muggia et al. 2015, 2016, 2017, 2019; Réblová et al. 2017a,b; Teixeira et al. 2017; Voglmayr et al. 2019; Quan et al. 2020). The use of the single locus nucLSU is due to the fact that sequence data for other loci, such as nucSSU, $\mathrm{mtSSU}$, or RPB $1 / 2$, are missing for the majority of the considered taxa. Although our choice to use a single genetic marker departs from the more conventional multilocus approach, in which several markers are combined to find higher support for the final topology, the majority of the taxa included here have been already analyzed in multilocus datasets which showed congruent results. 


\section{The new family Pleostigmataceae and basal lineages within Chaetothyriomycetidae}

Our phylogenetic inference of the orders in the subclass Chaetothyriomycetidae and the placement of lichencolonizing black fungi comprised all recognized orders and families (for which sequences of the nucLSU locus are available) and has led to a reappraisal of relationships and altered delimitation of some taxa. Since the pioneering molecular studies of lichenized and non-lichenized rock-inhabiting fungi in Eurotiomycetes by Ruibal et al. $(2005,2008)$ and Gueidan et al. $(2007,2008,2011)$, the class underwent various "adjustments" to reliably place the clades that emerged from sequence data. All these fungi are of great interest because they evolved different lifestyles albeit being closely related and sharing common ancestors (Gueidan et al. 2008, 2011).

Gueidan et al. (2014) recognized four orders in Chaetothyriomycetidae (Celotheliales, Chaetothyriales, Pyrenulales, and Verrucariales) comprising ten families and indicated three unnamed lineages. A more recent outline of Fungi by Wijayawardene et al. (2020) reported the same four orders but 16 families (ten families recognized within Chaetothyriales, four in Verrucariales and one in Phaeomoniellales and Pyrenulales). In the present phylogeny, as well as in previous studies, Pyrenulales and Phaeomoniellales invariably took the most basal positions (Gueidan et al. 2014; Réblová et al. 2017a,b; Muggia et al. 2016, 2017; Voglmayr et al. 2019). While Pyrenulales has been recognized a long time ago, Phaeomoniellales was introduced only recently by Chen et al. (2015) and confirmed by Réblová et al. (2017a,b), to accommodate endophytic and plant-pathogenic fungi of the genera Celothelium, Dolabra, Moristoma, Phaeomoniella, and Xenocylindrosporium. Phaeomoniellales corresponds to the family/order clade Celotheliaceae/Celotheliales which was proposed ad interim by Gueidan et al. (2014).

Verrucariales, with its single family Verrucariaceae, has been recovered as a fully supported monophyletic group and includes lichenized fungi forming crustose, squamulose, and foliose thalli (Gueidan et al. 2007, 2009; Muggia et al. 2010), associating with multiple lineages of microalgae (Thüs et al. 2011). They colonize various, mainly rocky, habitats ranging from marine and fresh water to arid environments (Gueidan et al. 2007; Muggia et al. 2010). Recently, Muggia et al. (2019) identified a new lineage of endolichenic black fungi within Verrucariaceae, which was provisionally named "Muellerella sp. 2," as the generic type species could not be sequenced so far. This group may represent the lichenicolous genus Muellerella.

The "unnamed lineage 1" recognized by Gueidan et al. (2014) included two species of Sclerococcum and two of Dactylospora and corresponded to "clade C" of Diederich et al. (2013), in which these two genera of lichenicolous fungi were judged to be closely related. This "unnamed lineage 1" was named "Dactylospora-clade" by Chen et al. (2015), while later, Réblová et al. (2017a) introduced the new family Sclerococcaceae for this group, and accommodated it in the new order Sclerococcales and the new subclass Sclerococcomycetidae within Eurotiomycetes. Within Sclerococcales, the authors accommodated, together with lichenicolous species of Sclerococcum and Dactylospora, some marine and lignicolous Dactylospora species, the lignicolous genus Rhopalophora, and other fungi from the digestive tracts of Neotropical wood-inhabiting beetles, as all these taxa formed a strongly supported, monophyletic clade that is basal to Chaetothyriomycetidae (i.e., Sclerococcales). In a more recent taxonomic revision of lichenicolous fungi by Diederich et al. (2018), the two genus names Dactylospora and Sclerococcum were recognized to be synonymous and Sclerococcum was set as the valid genus name, as it pre-dates Dactylospora. Family and order names were maintained as Dactylosporaceae and Sclerococcales, respectively (Diederich et al. 2018). The new subclass Sclerococcomycetidae was recognized also by Voglmayr et al. (2019) in their phylogenetic inference supporting the description of the two new classes, Xylobotryomycetes and Candelariomycetes (Ascomycota). The new taxonomy of Sclerococcales seems to have been overlooked by Ekanayaka et al. (2019) who recently introduced the order Dactylosporales and family Dactylosporaceae for a corresponding phylogenetic lineage within Eurotiomycetes. In our phylogenetic reconstruction, we selected samples of the lichenicolous species Sclerococcum sphaerale and the marine species Sclerococcum haliotrephum to represent the order clade Sclerococcales.

The second "unnamed lineage 2" of Gueidan et al. (2014) consisted of two unidentified rock isolates (A14, TRN242), Pleostigma jungermannicola M174 and Teichospora sp. M195. The lineage resulted as a sister clade of Verrucariales. The same, well-supported lineage of Pleostigma jungermannicola M174 and Teichospora sp. M195 was recognized by Stenroos et al. (2010) in their fivegene phylogeny when investigating the multiple origins of symbiosis between ascomycetes and bryophytes. "Unnamed lineage 2" was found to be monophyletic and well-supported by Gueidan et al. (2014), but completely paraphyletic and closely related to Verrucariales by Chen et al. (2015), who maintained the label "unknown lineage." The sample of Teichospora sp. M195 used by Stenroos et al. (2010), Gueidan et al. (2014), and Chen et al. (2015) is likely to represent an unknown taxon or a contamination, because the type species of Teichospora and the family Teichosporaceae was revealed to be a member of Pleosporales in the class Dothideomycetes (Jaklitsch et al. 2016). For this reason, we excluded the sequence of Teichospora sp. M195 from our analysis. The "unnamed lineage 2," referred to as 
"Pleostigma-clade," was represented by Pleostigma jungermannicola only in the study of Ekanayaka et al. (2019). Réblová et al. (2017a) did not include this lineage in their description of the new order Sclerococcales, but they considered it when describing the two new genera Bradymyces (Trichomeriaceae) and Bacillicladium (undetermined position in Chaetothyriales; Réblová et al. 2017b). Boonmee et al. (2017), when revising genera of ascomycete of incertae sedis, reported that "based on sequence data, the genus Pleostigma is treated as incertae sedis in Chaetothyriales." In our present analysis, the three taxa representing the "unnamed lineage 2" sensu Gueidan et al. (2014), i.e., Chaetothyriales spp. A14, TRN242 and Pleostigma jungermannicola M174, cluster together with strains of lichen-associated black fungi that formed the lineages "clade IV" and "clade V" in Muggia et al. (2016, 2017). This lineage is now formally described as the family Pleostigmaceae with three lichen-associated molecular species, which however lack distinctive morphological traits. The rockinhabiting fungus Chaetothyriales TRN242 is closely related to six samples of lichen-associated black fungi basal to P. frigida. These lichen-associated strains are morphologically identical to $P$. frigida, but due to their significant genetic distance, we refrain to merge them. Chaetothyriales sp. A14 and Pleostigma jungermannicola M174 on individual branches represent separate species. The lineage Pleostigmaceae, though individually monophyletic, is not supported in the present analysis and its phylogenetic position might undergo variation if a different taxon sampling is investigated. For this reason, we opt here to define it as a new family with still an uncertain position within Chaetothyriomycetidae. However, we do believe that its establishment as a new family is reasonable and warranted: it now delimits a monophyletic taxonomic entity that has been identified since 2010 and has been confirmed by a substantial number of samples in the present study.

\section{The new genus Melanina and basal lineages within Chaetothyriales}

The third "unnamed lineage 3" is represented by three strains of rock-inhabiting fungi, TRN210, TRN508, and TRN515 (Gueidan et al. 2014); all isolates originated from natural rocks in the Mediterranean basin (Ruibal et al. 2008). This clade has consistently been recovered within Chaetothyriales (Ruibal et al. 2008; Gueidan et al. 2014; Réblová et al. 2017a; Muggia et al. 2016, 2017), with slight changes in phylogenetic position, probably depending on different taxon samplings. Gueidan et al. (2014) considered "unnamed lineage 3" to be basal to Cyphellophoraceae, Chaetothyriaceae, and Trichomeriaceae, while it was sister to Cyphellophoraceae in Réblová et al. (2017b). This "unnamed lineage 3" corresponds to the lineage "clade VI + VII" of Muggia et al. (2016, 2017), and is formalized here as the novel genus Melanina. The rockinhabiting fungi (TRN210 and TRN508) of "unnamed lineage 3 " cluster with strains isolated from lichens. This suggests that these fungi are widespread in multiple rocky environments, either in association with lichens, or free-living. In our analysis, Melanina has a basal position to most Chaetothyriales except for the family Epibryaceae and the lineage composed by Muellerella atricola, M. lichenicola, and their Lichenodiplis-like asexual fungus.

The family Epibryaceae includes the genus Epibryon, some species described as Cladophialophora (Quan et al. 2020), and some unnamed fungi isolated from rock (TRN475) and from lichens (A515). Depending on taxon sampling, the family Epibryaceae has been recovered as either monophyletic with low support (Gueidan et al. 2014; Muggia et al. 2016, 2017; Réblová et al. 2017b; Teixeira et al. 2017) or paraphyletic (Muggia et al. 2019; Quan et al. 2020). As in this study, Stenroos et al. (2010) and Quan et al. (2020) also found the genus to consist of two separate clades, suggesting that future, in-depth analyses might lead to a reconsideration of the genus in its whole.

The clade containing Muellerella atricola, M. lichenicola, and a Lichenodiplis-like species was recognized by Muggia et al. $(2015,2019)$ including some perithecia-forming lichenicolous fungi with their asexual, pycnidial state referred to as Lichenodiplis. Since fungi ascribed to the genus Muellerella were found to be polyphyletic within Chaetothyriomycetidae, while its type species, M. polyspora has not been sequenced yet, the name Muellerella cannot be applied with certainty to any of these fungi (Muggia et al. 2019).

The remaining four families Chaetothyriaceae, Cyphellophoraceae, Herpotrichiellaceae, and Trichomeriaceae are monophyletic, fully resolved and well-supported, and their species and ecological diversity have been the focus of recent phylogenetic and phylogenomic studies (Teixeira et al. 2017; Gostinčar et al., 2018; Quan et al. 2020). The Trichomeriaceae comprises the "sooty molds" that colonize inert surfaces (Chomnunti et al. 2012). The derived family Herpotrichiellaceae includes black yeasts and relatives, which have very different habitat choices, often characterized by extreme conditions and oligotrophy (de Hoog, 2016). These fungi are unique for their polyextremotolerance and opportunistic pathogenicity in humans (de Hoog et al., 2020). Five strains of lichen-associated black fungi are nested in the Cladophialophora-clade in Herpotrichiellaceae.

\section{Lifestyles of lichen-associated fungi and basal line- ages within Chaetothyriomycetidae}

Trophic interactions between lichen-associated black fungi and their hosts are still poorly understood. This is mainly because microscopic analyses of lichen thalli do not allow to 
clearly localize the endolichenic fungi inside the thalli. Furthermore, these fungi neither produce clear infection structures with the host's photobiont, nor they show any mycoparasitic behavior towards the mycobiont. In the cases where black fungal hyphae have been detected in different layers of the lichen thalli, the hyphae were observed to spread randomly without forming any structure inside the lichen (M. Grube, unpubl. results). In most cases, individually melanized hyphae were seen between the hyphae of the upper cortex of epilithic crustose lichens, or growing in between the areoles of the thallus, in which thin fissures are formed due to the discontinuous growth of the thallus. These thin fissures may also act as spaces where airborne spores and fungal fragments remain trapped and might grow and extend inside the lichen thalli. Consequently, we hypothesize that these black fungi are commensals that seem to benefit from compounds exuded into the intercellular matrix of the conglutinate fungal plectenchyma. This does not exclude that the algal partner of the lichen may have some effect on the growth of lichenassociated fungi. Earlier studies demonstrated an affinity of a lichen-inhabiting black fungus to microalgae during axenic co-cultivation with the principal photobiont of the host (Gorbushina et al. 2005; Brunauer et al. 2007). In natural habitats, particularly in calcareous rock environments, black fungi are known to establish communities with green algae and cyanobacteria either along crevices or endolithic in the weathering rinds of the rocks (Gorbushina and Broughton 2009; Gostinčar et al. 2012). The potential for these fungal lineages to associate and grow with microalgae suggests that primitive fungal-algal interactions may be involved (Gostinčar et al., 2012; Ametrano et al. 2017, 2019a).

The two new lineages Pleostigmataceae and Melanina have not been tested for their capacity to associate with microalgae. However, their phylogenetic position as inferred in the present paper supports their close affiliation to bryosymbiotic taxa, lichen-forming fungi, and lichen pathogens. Indeed, species of lichen-associated Pleostigma are closely related to the bryosymbiotic taxon Pleostigma jungermannicola. Melanina, on the other hand, is basal to the families Herpotrichiellaceae, Chaetothyriaceae, Cyphellophoraceae, and Trichomeriaceae. Chaetothyriaceae and Trichomeriaceae are surface colonizers of plants and inert substrates, respectively, while the remaining families show a high ecological diversity (Quan et al. 2020). The ancestral clades (i.e., Epibryaceae, Melanina, and the Muellerella atricola + M. lichenicola + Lichenodiplis-like asexual state) of these core-families of Chaetothyriales are all associated with rocks, lichens, or bryophytes as a rather strong apomorphic/ancestral character, which is maintained across the evolution of Chaetothyriomycetidae (Gueidan et al. 2008, 2011; Quan et al. 2020).
Interestingly, in both Pleostigmaceae and Melanina, a certain heterogeneity of hyphae can be discerned, hyphal cells being either rectangular, elongated, with frequent branching, or subspherical and budding, sometimes forming short chains. Similar morphology is found in other lineages of rockinhabiting fungi in Dothideomycetes and Chaetothyriales (Egidi et al. 2014; Ametrano et al. 2019b). Poor morphological differentiation is indeed common among these fungi in general, and although these fungi have substantially diversified phylogenetically, they share morphological and functional traits which indicate adaptation to similar types of abiotic stresses.

Supplementary Information The online version contains supplementary material available at https://doi.org/10.1007/s11557-021-01706-8.

Acknowledgements Theodora Kopun, Doris Feiertag, and Sigrun Kraker are thanked for the support in the lab work.

Availability of data and material Data and materials are available at NCBI GenBank.

Code availability Not applicable.

Author contribution LM and SH designed the work; LM and YQ analyzed the data. All authors contributed in writing the manuscript.

Funding Open access funding provided by Università degli Studi di Trieste within the CRUI-CARE Agreement.

\section{Declarations}

Conflict of interest The authors declare no competing interests.

Open Access This article is licensed under a Creative Commons Attribution 4.0 International License, which permits use, sharing, adaptation, distribution and reproduction in any medium or format, as long as you give appropriate credit to the original author(s) and the source, provide a link to the Creative Commons licence, and indicate if changes were made. The images or other third party material in this article are included in the article's Creative Commons licence, unless indicated otherwise in a credit line to the material. If material is not included in the article's Creative Commons licence and your intended use is not permitted by statutory regulation or exceeds the permitted use, you will need to obtain permission directly from the copyright holder. To view a copy of this licence, visit http://creativecommons.org/licenses/by/4.0/.

\section{References}

Ametrano CG, Selbmann L, Muggia L (2017) A standardized approach for co-culturing Dothidealean rock-inhabiting fungi and lichen photobionts in vitro. Symbiosis 73:35-44

Ametrano CG, Grewe F, Crous PW, Goodwin SB, Liang C, Selbmann L, Lumbsch HT, Leavitt SD, Muggia L (2019a) Genome-scale data 
resolve ancestral rock-inhabiting lifestyle in Dothideomycetes (Ascomycota). IMA Fungus 10:19

Ametrano C, Knudsen K, Kocourkova J, Grube M, Selbmann L, Muggia L (2019b) Phylogenetic relationships of rock-inhabiting black fungi belonging to the widespread genera Lichenothelia and Saxomyces. Mycologia 111:127-160

Arnold AE, Miadlikowska J, Higgins KL, Sarvate SD, Gugger P, Way A, Hofstetter V, Kauff F, Lutzoni F (2009) A phylogenetic estimation of trophic transition networks for ascomycetous fungi: are lichens cradles of symbiotrophic fungal diversification? Syst Biol 58:283297

Banchi E, Stanković D, Fernandez-Mendoza F, Gionechetti F, Palavicini A, Muggia L (2018) ITS2 metabarcoding analysis complements lichen mycobiome diversity data. Mycol Prog 17:1049-1066

Boonmee S, Phookamsak R, Hongsanan S, Doilom M, Mapook A, McKenzie EHC, Bhat DJ, Hyde KD (2017) Mycosphere notes 51101. Revision of genera in Perisporiopsidaceae and Pseudoperisporiaceae and other Ascomycota genera incertae sedis. Mycosphere 8(10):1695-1801

Brunauer G, Blaha J, Hager A, Türk R, Stocker-Wörgötter E, Grube M (2007) Lichenoid structures in vitro of a cultured lichenicolous fungus. Symbiosis 44:127-136

Chen KH, Miadlikowska J, Molnar K, Arnold AE, U'Ren JM, Gaya E, Gueidan C, Lutzoni F (2015) Phylogenetic analyses of eurotiomycetous endophytes reveal their close affinities to Chaetothyriales, Eurotiales and a new order-Phaeomoniellales. Mol Phylogenet Evol 85:117-130

Chomnunti P, Bhat DJ, Gareth Jones EB, Chukeatirote E, Bahkali AH, Hyde KD (2012) Trichomeriaceae, a new sooty mould family of Chaetothyriales. Fungal Divers 56:63-76

de Hoog GS (2016) Ecology and phylogeny of black yeast-like fungi: diversity in unexplored habitats. Fungal Divers 65:1-2

de Hoog GS, Guarro J, Gené J, Ahmed SA, Al-Hatmi AMS, Figueras MJ, Vitale RG (2020) Atlas of clinical fungi, 4th edn. Foundation Atlas of Clinical Fungi, Hilversum

de los Rios A, Ascaso C, Grube M (2002) Infection mechanisms of lichenicolous fungi studied by various microscopic techniques. Bibl Lichen 82:153-161

Diederich P, Ertz D, Lawrey JD, Sikaroodi M, Untereiner MA (2013) Molecular data place the hyphomycetous lichenicolous genus Sclerococcum close to Dactylospora (Eurotiomycetes) and S. parmeliae in Cladophialophora (Chaetothyriales). Fungal Divers 58:61-72

Diederich P, Lawrey JD, Ertz D (2018) The 2018 classification and checklist of lichenicolous fungi, with 2000 non-lichenized, obligately lichenicolous taxa. Bryologist 121:340-425

Egidi E, de Hoog GS, Isola D, Onofri S, Quaedvlieg W, de Vries M, Verkley GJM, Steilow JB, Zucconi L, Selbmann L (2014) Phylogeny and taxonomy of meristematic rock-inhabiting black fungi in the Dothideomycetes based on multi-locus phylogenies. Fungal Divers 65:127-165

Ekanayaka AH, Jones EBG, Hyde K, Zhao Q (2019) A stable phylogeny for Dactylosporaceae. Cryptogam Mycol 40:23-44

Ertz D, Heuchert B, Braun U, Freebury CE, Common RS, Diederich P (2016) Contributionto the phylogeny and taxonomy of the genus Taeniolella with a focus on lichenicolous taxa. Fung Biol 120: 1416-1447

Fernandez-Mendoza F, Kopun T, Fleischhacker A, Grube M, Muggia L (2017) ITS1 metabarcoding highlights low specificity of lichen mycobiomes at local scale. Mol Ecol 26:4811-4830

Fleischhacker A, Grube M, Kopun T, Hafellner J, Muggia L (2015) Community analyses uncover high diversity of lichenicolous fungi in alpine habitats. Microb Ecol 70:348-360

Gorbushina AA, Broughton WJ (2009) Microbiology of the atmosphererock interface: how biological interactions and physical stresses modulate a sophisticated microbial ecosystem. Annu Rev Microbiol 63:431-450

Gorbushina AA, Beck A, Schulte A (2005) Microcolonial rock inhabiting fungi and lichen photobionts: evidence for mutualistic interactions. Mycol Res 109:1288-1296

Gostinčar C, Muggia L, Grube M (2012) Polyextremotolerant black fungi: oligotrophism, adaptive potential, and a link to lichen symbioses. Front Microbiol 3:390

Gostinčar C, Zajc J, Lenassi M, Plemenitaš A, de Hoog S, Al-Hatmi AM, Gunde-Cimerman N (2018) Fungi between extremotolerance and opportunistic pathogenicity on humans. Fungal Divers 93:195-213

Grube M, Cardinale M, Vieira De Castro J, Müller H, Berg G (2009) Species-specific structural and functional diversity of bacterial communities in lichen symbiosis. ISME J 3:1105-1115

Grube M, Cernava T, Soh J, Fuchs S, Aschenbrenner I, Lassek C, Wegner U, Becher D, Riedel K, Sensen CW, Berg G (2015) Exploring functional contexts of symbiotic sustain within lichenassociated bacteria by comparative omics. ISME J 9:412-424

Gueidan C, Roux C, Lutzoni F (2007) Using a multigene phylogenetic analysis to assess generic delineation and character evolution in Verrucariaceae (Verrucariales, Ascomycota). Mycol Res 111: $1145-1168$

Gueidan C, Ruibal Villaseñor C, de Hoog GS, Gorbushina AA, Untereiner WA, Lutzoni F (2008) A rock-inhabiting ancestor for mutualistic and pathogen-rich fungal lineages. Stud Mycol 61: 111-119

Gueidan C, Savić S, Thüs H, Roux C, Keller C, Tibell L, Prieto M, Heiðmarsson S, Breuss O, Orange A, Fröberg L, Amtoft-Wynns A, Navarro-Rosinés P, Krzewicka B, Pykälä J, Grube M, Lutzoni F (2009) Generic classification of the Verrucariaceae (Ascomycota) based on molecular and morphological evidence: recent progress and remaining challenges. Taxon 58:184-208

Gueidan C, Ruibal C, de Hoog GS, Schneider H (2011) Rock-inhabiting fungi originated during periods of dry climate in the late Devonian and middle Triassic. Fung Biol 115:987-996

Gueidan C, Aptroot A, Silvia Caceres ME, Badali H, Stenroos S (2014) A reappraisal of orders and families within the subclass Chaetothyriomycetidae (Eurotiomycetes, Ascomycota). Mycol Prog 13:1027-1039

Gueidan C, Elix JA, McCarthy PM, Roux C, Mallen-Cooper M, Kantvilas G (2019) PacBio amplicon sequencing for metabarcoding of mixed DNA samples from lichen herbarium specimens. MycoKeys 53:73-91

Hall TA (1999) BioEdit: a user friendly biological sequence alignment editor and analysis program for Windows 95/98/NT. Nuc Ac Symp Series 41:95-98.9

Harutyunyan S, Muggia L, Grube M (2008) Black fungi in lichens from seasonally arid habitats. Stud Mycol 61:83-90

Hawksworth DL, Honegger R (1994) The lichen thallus: a symbiotic phenotype of nutritionally specialized fungi and its response to gall producers. In Systematics association special volume, Williams, M.A.J. Ed.; Clarendon Press: Oxford, United Kingdom, 1994; pp $77-98$

Hofstetter V, Miadlikowska J, Kauff F, Lutzoni F (2007) Phylogenetic comparison of protein-coding versus ribosomal RNA-coding sequence data: a case study of the Lecanoromycetes (Ascomycota). Mol Phylogenet Evol 44:412-426

Jaklitsch WM, Olariaga I, Voglmayr H (2016) Teichospora and the Teichosporaceae. Mycol Prog 15:31

Lawrey JD, Diederich P (2003) Lichenicolous fungi: interactions, evolution, and biodiversity. Bryologist 106:80-120

Lendemer JC, Keepers KG, Tripp EA, Pogoda CS, McCain CM, Kane NC (2019) A taxonomically broad metagenomic survey of 339 species spanning 57 families suggests cystobasidiomycete yeasts are not ubiquitous across all lichens. Am J Bot 106:1090-1095 
Mason-Gamer R, Kellogg E (1996) Testing for phylogenetic conflict among molecular dataset in the tribe Triticeae (Gramiae). Syst Biol 45:524-545

Molins A, Moya P, García-Breijo FJ, Reig-Armiñana J, Barreno E (2018) A multi-tool approach to assess microalgal diversity in lichens: isolation, Sanger sequencing, HTS and ultrastructural correlations. Lichenologist 50:123-138

Moya P, Molins AA, Ânez-Alberola FM, Muggia L, Barreno E (2017) Unexpected associated microalgal diversity in the lichen Ramalina farinacea is uncovered by pyrosequencing analyses. PLoS One 12: e0175091

Muggia L, Grube M (2018) Fungal diversity in lichens: from extremotolerance to interaction with algae. Life 8:15

Muggia L, Gueidan C, Grube M (2010) Phylogenetic placement of some morphologically unusual member of Verrucariaceae. Mycologia 102:835-846

Muggia L, Kopun T, Ertz D (2015) Phylogenetic placement of the lichenicolous, anamorphic genus Lichenodiplis and its connection to Muellerella-like teleomorphs. Fung Biol 119:1115-1128

Muggia L, Fleischhacker A, Kopun T, Grube M (2016) Extremotolerant fungi from alpine rock lichens and their phylogenetic relationships. Fungal Divers 76:119-142

Muggia L, Kopun T, Grube M (2017) Effects of growth media on the diversity of culturable fungi from lichens. Molecules 22:824

Muggia L, Pérez-Ortega S, Ertz D (2019) Muellerella, a lichenicolous fungal genus recovered as polyphyletic within Chaetothyriomycetidae (Eurotiomycetes, Ascomycota). Plant Fung Syst 64:367-381

Page RDM (1996) TREEVIEW: an application to display phylogenetic trees on personal computers. Comput Appl Biosci 12:357-358

Petrini O, Hake U, Dreyfuss MM (1990) An analysis of fungal communities isolated from fruticose lichens. Mycologia 82:444-451

Quan Y, Muggia L, Moreno LF, Wang MZ, Al-Hatmi AMS, Menezes da Silva N, Shi DM, Deng SW, Ahmed SA, Stielow BJ, Qing T, Hyde KD, Kang YQ, de Hoog GS (2020) A re-evaluation of the Chaetothyriales using criteria of phylogeny and ecology. Fungal Divers 103:47-85

Réblová M, Untereiner WA, Štěpánek V, Gams W (2017a) Disentangling Phialophora section Catenulatae: disposition of taxa with pigmented conidiophores and recognition of a new subclass, Sclerococcomycetidae (Eurotiomycetes). Mycol Prog 16:27-46

Réblová M, Hubka V, Thurenborn O, Lundberg J, Sallstedt T, Wedin M, Ivarsson M (2017b) From the tunnels into the treetops: new lineages of black yeasts from biofilm in the Stockholm Metro System and their relatives among ant-associated fungi in the Chaetothyriales. PlosONE 11(10):e0163396

Reeb V, Lutzoni F, Roux C (2004) Contribution of RPB2 to multilocus phylogenetic studies of the euascomycetes (Pezizomycotina, Fungi) with special emphasis on the lichen-forming Acarosporaceae and evolution of polyspory. Mol Phylogenet Evol 32:1036-1060

Ronquist F, Huelsenbeck JP, Teslenko M (2011) MrBayes version 3.2 Manual: tutorials and Model Summaries. https://nbisweden.github. io/MrBayes/manual.html

Ruibal C, Gonzalo P, Bills GF (2005) Isolation and characterization of melanized fungi from limestone formation in Mallorca. Mycol Prog 4:23-38

Ruibal T, Platas G, Bills GF (2008) High diversity and morphological convergence among melanised fungi from rock formations in the Central Mountain System of Spain. Persoonia 21:93-110

Smith H, Dal Grande F, Muggia L, Keuler R, Divakar PK, Grewe F, Schmitt I, Lumbsch HT, Lavitt SD (2020) Data mining metagenomic sequencing reads reveals diverse, lichen-specific mycobiomes. Symbiosis 82:133-147
Spribille T (2018) Relative symbiont input and the lichen symbiotic outcome. Curr Opin Plant Biol 44:57-63

Spribille T, Tuovinen V, Resl P, Vanderpool D, Wolinski H, Aime MC, Schneider K, Stabentheiner E, Toome-Heller M, Thor G, Mayrhofer H, Johannesson H, McCutcheon JP (2016) Basidiomycete yeasts in the cortex of ascomycete macrolichens. Science 353:488-492

Stamatakis A (2014) RAxML version 8: a tool for phylogenetic analysis and post-analysis of large phylogenies. Bioinformatics, http:// bioinformatics.oxfordjournals.org/

Stenroos S, Laukka T, Huhtinen S, Döbbler P, Myllys L, Syrjänen K, Hyvönen J (2010) Multiple origin of symbiosis between ascomycetes and bryophytes suggested by a five-gene phylogeny. Cladistic 26:281-300

Suija A, Ertz D, Lawrey JD, Diedetrich P (2015) Multiple origin of the lichenicolous life habit in Helotiales, based on nuclear ribosomal sequences. Fun Div 70:55-72

Teixeira MM, Moreno LF, Stielow BJ, Muszewska A, Hainaut M, Gonzaga L, Abouelleil A et al (2017) Exploring the genomic diversity of black yeasts and relatives (Chaetothyriales, Ascomycota). Stud Mycol 86:1-28

Thüs H, Muggia L, Pérez-Ortega S, Favero-Longo SE, Joneson S, O’Brien H, Nelsen MP, Duque-Thüs R, Grube M, Friedl T, Brodie J, Andrew CJ, Lücking R, Lutzoni F, Gueidan C (2011) Revisiting photobiont diversity in the lichen family Verrucariaceae (Ascomycota). Eur J Phycol 46:399-415

U'Ren JM, Lutzoni FM, Miadlikowska J, Arnold AE (2010) Community analysis reveals close affinities between endophytic and endolichenic fungi in mosses and lichens. Microb Ecol 60:340-353

U'Ren JM, Lutzoni F, Miadlikovska J, Laetsch AD, Arnold AE (2012) Host and geographic structure of endophytic and endolichenic fungi at a continental scale. Am J Bot 99:898-914

U'Ren JM, Lutzoni F, Miadlikowska J, Zimmerman NB, Carbone I, May G, Arnold AE (2019) Host availability drives distributions of fungal endophytes in the imperilled boreal realm. Nat Ecol Evol 3:1430 1437

Untereiner WA, Gueidan C, Orr MJ, Diederich P (2011) The phylogenetic position of the lichenicolus ascomycete Capronia peltigerae. Fungal Divers 49:225-233

van Husen D (1987) Die Ostalpen in den Eiszeiten. Geologische Bundesanstalt, Wien

Vasse M, Voglmayer H, Mayer V, Gueidan C, Nepel M, Moreno L, de Hoog S, Selosse M-A, McKey D, Blatrix R (2017) A phylogenetic perspective on the association between ants (Hymenoptera: Formicidae) and black yeasts (Ascomycota: Chaetothyriales). Proc R Soc B 284:20162519

Vilgalys R, Hester M (1990) Rapid genetic identification and mapping of enzymatically amplified ribosomal DNA from several Cryptococcus species. J Bacteriol 172:4238-4246

Voglmayr H, Fournier J, Jaklitsch WM (2019) Two new classes of Ascomycota: Xylobotryomycetes and Candelariomycetes. Persoonia 42:36-49

Wijayawardene NN, Hyde KD, Khalil Tawfeeq Al-Ani L, Tedersoo L et al (2020) Outline of fungus and fungi-like taxa. Mycosphere 11 (in press)

Yamamoto Y, Kinoshita Y, Yoshimura I (2002) Culture of thallus fragments and re-differentiation of lichens. In: Kanner I, Beckett RP, Varma AK (eds) Protocol in lichenology, culturing biochemistry, ecophysiology and use in biomonitoring. Springer, Berlin, Germany, pp 34-46

Publisher's note Springer Nature remains neutral with regard to jurisdictional claims in published maps and institutional affiliations. 